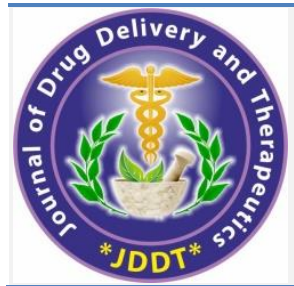

Open Access Full Text Article

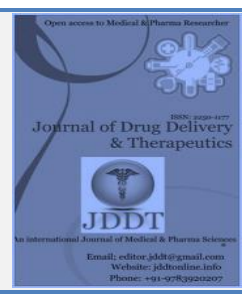

\title{
Content Validity Determination of the Suicidal Ideation Behaviour Assessment Instruments Using Content Validity Ratio (CVR) Formula
}

\author{
Norshahira, $\mathrm{O}^{1 *}$, Norashida, S. $\mathrm{R}^{2}$, Lukman, Z. $\mathrm{M}^{3}$ \\ ${ }^{1}$ Master of Social Work, Faculty of Applied Social Sciences, University Sultan Zainal Abidin, Kuala Nerus, 20300, Terengganu, Malaysia \\ ${ }^{2}$ Master of Social Work, Faculty of Applied Social Sciences, University Sultan Zainal Abidin. Kuala Nerus, 20300, Terengganu, Malaysia \\ ${ }^{3}$ Professor, Faculty of Applied Social Sciences, University Sultan Zainal Abidin, Kuala Nerus, 20300, Terengganu, Malaysia
}

\section{Article Info:}

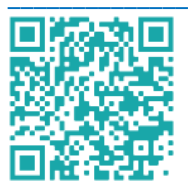

\section{Article History:}

Received 21 June 2021

Reviewed 25 July 2021

Accepted 03 Aug 2021

Published 15 August 2021

\section{Cite this article as:}

Norshahira, O, Norashida S. R, Lukman Z. M, Content Validity Determination of the Suicidal Ideation Behaviour Assessment Instruments Using Content Validity Ratio (CVR) Formula, Journal of Drug Delivery and Therapeutics. 2021; 11(4-S):81-

DOI: http://dx.doi.org/10.22270/jddt.v11i4-S.4968

\section{*Address for Correspondence:}

Norshahira Binti Osman, Master of Social Work, Faculty of Applied Social Science, University Sultan Zainal Abidin, Kuala Nerus, 20300, Terengganu, Malaysia

\section{Abstract}

Drug addiction problems have been identified as one of the high-risk factors closely linked to suicidal behaviour. Early detection of suicidal intent among addicts is important to ensure they do not take actions that could result in death. Accordingly, this study aimed to Suicidal Ideation Behaviour Assessment (SIBA) instruments specifically among 123 treated addicts in Cure and Care Rehabilitation Centre (CCRC), Besut. Based on those statements, the main objective of this study was to determine the content validity of SIBA instruments for using the content validation Ratio (CVR) method. Subjects that were involved in conducting the trial of the instruments were 8 experts from UniSZA, UPSI and UMT. The instrument validation process involved 40 items from four components. The previous study found that the instrument had high validity with the minimum level of CVR value $(\mathrm{N}=8, \mathrm{CVR}=0.88)$. Generally, all items were identified with values above 0.63 rated acceptable and no item has been rejected occur. The result showed that the instrument is appropriate, relevant, has the potential to be a good content validity and proved that SIBA has a great potential to be promoted as a good instrument. This study was conducted to detect intoxication of their suicidal ideation among drug addicts. This psychometric instrument is developed based on the situation in Malaysia. This study is expected to make a significant contribution to the government, especially the CCRC in assisting addicts with suicidal ideation behaviour by providing better attention and psychosocial support services.

Keywords: Suicide ideation, drug addict, content validity ratio, instrument

\section{INTRODUCTION}

Suicide is a health problem worldwide. Drug users are primarily documented as a high-risk population of suicidal ideation behaviour since drug use can exert a negative impact on individuals' health and mental health. 1,2,3,4 Without us realizing it, the development of this suicidal desire behaviour is becoming more prevalent globally. 5,6,7 In Malaysia, the suicide rate was 7.85 per 100,000 people in 2017. While the suicide rate in Malaysia was lower than that of the global rate, the number of suicide deaths was still high and ranked 146th in the world in suicide cases. ${ }^{8}$ Therefore, Individuals as drug addicts are at higher risk for suicide than those who do not use drugs. $9,10,11$

Under such a context, the studies on drug users' suicidal ideation behaviour instrument are much needed. it helps addicts in detecting suicidal behaviour. Therefore, this study uses the Suicidal Ideation Behaviour Assessment (SIBA) Instrument is to measure the stage of suicide ideation behaviour among drug addicts based on the context of the Malaysian environment. This study helps the government and Private Drug Rehabilitation Centre to develop the instrument and analyse the stage of addiction recovery in drug addicts. This study highlights four components namely conflict interpersonal, emotional disorder, depression and hopelessness based on previous research. However, SIBA instrument can be used well, if it has good evaluation tools. The evaluation tools needed are evaluation instruments. 12 The assessment instruments needed in evaluating suicidal ideation behaviour must be valid. This is because there are still invalid instruments used to evaluate so that the impact on evaluation results is not optimal. For the development of this SIBA instrument, the validity of this content should be done so that the component measuring instrument can be measured accurately. 13 Although the instrument has excellent reliability but if the psychometric characteristics of the instrument are affected then there is no satisfactory validity. ${ }^{14}$ The validation process will ensure the instrument has defensible, appropriate, accurate, useful and meaningful properties. 15,16 It facilitates the validation process to be done accurately to develop a valid instrument for use. ${ }^{16,17}$ In general, 13, 18 CVR methods have been used by local and foreign researchers as an initial step in the instrument preparation process. 19.20

Based on these conditions, researchers were interested in researching on the content validity of the SIBA instruments which can later be used as an evaluation tool of suicidal ideation behaviour at CCRC Besut, Malaysia in particular. In 
this section, the questionnaire was validated by eight experts selected according to their experience in a specific field of research from University Sultan Zainal Abidin (UniSZA), University Malaysia Terengganu (UMT) and University Pendidikan Sultan Idris (UPSI). The instrument is then examined, studied and evaluated for its accuracy as well as examining the fundamental factors for each item constructed by the researcher in detail.

\section{MATERIALS AND METHODS}

This research is instrument development research, which focuses on determining the validity of the content of SIBA instruments. Therefore, the purpose of this study was to test the validity of the instrument content in the constructed study. Some tests that have been performed are the item panel experiment test, tabulation of data from the experts' experiment, performing validity calculations using CVR Lawshe formula, interpretation of calculation results using the validity categorization table of the reference instrument 21,22. The formula for Lawshe's CVR can be shown in the equation, 23

\section{Table 1: Formula for Content Validity Ratios}

$$
\mathrm{CVR}=\underline{\mathrm{Ne}}-(\mathrm{N} / 2)
$$

\section{CVR= Content Validity Ratio}

$\mathrm{Ne}=\mathrm{A}$ number of experts who declare an item of importance

\section{$\mathrm{N}=$ The total number of experts Table}

However, this study has set for the selection of experts several criteria that have been met. For the purpose of data collection, this study uses a variety of face-to-face approaches or known as direct approaches, postal and online surveys such as email internet surveys following the comfort and needs of experts. 12,23 The study involved only eight experts to evaluate each item according to the SIBA component.

\section{RESULT}

The study uses instruments built by researchers and tested through a panel of experts or known as face validation. Facial validity is the extent to which the instrument is generally seen to be true to measure knowledge, behaviour, feelings and matters related to the instrument being constructed. It is the basis for the validation measurement in which the study takes place to measure accurately and in line with the objectives of the study. The purpose of this study should also relate to each item and questionnaire. 24 Instrument evaluation can be tested by an administration known as an expert. In this study, the supervisory committee of researchers was provided with the first version of the instrument so that they could verify it in several aspects such as word fit and accuracy of the instrument. This step has been done so that the problem of errors and ambiguity of the items in the instrument can be avoided before distribution to the respondents. The instrument also recommendations need to be evaluated by professionals and those who specialize in related fields. ${ }^{14}$ Therefore, ideas and improvements have been added to the research instrument.

Furthermore, this study refers to eight experts in a variety of fields namely the fields of psychometrics, analysis, psychology, validity analysis, item construction and recovery item construction. They consist of university lecturers and officials in the Ministry of Education Malaysia. Modifications were made repeatedly for each item produced so that the items could be measured in line with the objectives of the study. Each item is constructed according to the correct format structure setting i.e. each item is ensured in accordance with through instructions and clarity of meaning. 25 Each item structure was aligned according to the requirements of the study such as the objectives of the study, processing in terms of language use, the ability of the items to measure the components of the study and the absence of item repetition problems. Among the difficulties in forming SIBA instrument items is that the process of constructing these items takes a long time because all the remarks and comments given are received from experts to be repaired and applied. This is because, it is to strengthen the quality in terms of language, format and content of each item. This review takes place continuously until the expert is satisfied that the items in the instrument meet the objectives of the study, complete (comprehensive), applicability (applicability), meet the appropriateness of the criteria and each component can be identified. In total, the number of items can be produced as many as 40 items and broken down into four components, namely Interpersonal Conflict, Emotional Disorder, Depression and Hopelessness.

Moreover, the validity of this content is the extent to which the instrument accurately measures the component to be measured. Content validity indicates that the suitability and style of a particular test measures the elements for which it is set to measure. According to Delgado 13 identifying content validity as a sufficient level of instrumentation to construct a study. In this section, the constructed instruments have been validated by selected experts according to their experience in a particular field of research. In this study, the researcher has selected several experts to evaluate this SIBA instrument. Subsequently, these SIBA instruments are inspected, reviewed, assessed for accuracy and examine the fundamental factors of each number of items. Therefore, the selection of established items is a component. It is to identify whether this item is a construction item or not it must require proof. Therefore, evidence can be demonstrated through a content verification procedure. Content validation can be described as an assessment of the locality of an instrument. 1326 Thus, proposed several procedures in the study namely the definition of component concepts. The definition of a component concept is evidence of content validity depending on the accuracy and suitability of the specified component. ${ }^{27}$ Vague or inaccurate definitions tend to have poor understanding and are difficult to perform critical analysis based on concepts. In this study, the definition of the component concept has been determined in the previous chapter.

In addition, the components of this study aimed to measure suicidal ideation behaviours. To obtain the validity of its content, experts assess whether the item represents a component or not. Thus, a component expert is a committee that knows in a particular field. The goal of content validation is to examine items that represent components and their relevance. Items that have been developed will be evaluated and they will answer the question of whether they are (1) Essential (very important), (2) Useful but not essential (useful but not essential) or (3) Not necessary (not necessary). ${ }^{23}$ Each item will be analysed by how important it is. At least half of the experts agreed that the item was "important", so it was considered to have high content validity. ${ }^{23}$

Content validation instruments were distributed to the panel to demonstrate the importance of a particular item in evaluating the scale components. Domain experts are asked to select an appropriate assessment that indicates the level of importance of the item in measuring a particular 
component of the component. They should assess whether the ideas or statements described in each item are a) 'very important', b) 'useful', but not 'important', or c) 'unnecessary'. In the quantitative content validation process, CVR was calculated for 40 items with a panel of eight subject matter experts.

Content validation includes an appropriate assessment that symbolizes the item's requirements. The CVR for the specified component was calculated. The results of the CVR implementation are as illustrated in Table 2 to 5 . With a measure of eight panels, Lawshe 23 suggested that the minimum indicator of CVR acceptance item value is 0.62 . After the CVR value for each item is identified, items that are below the value of 0.20 will be dropped or have very low validity. Through the determination of CVR values that have been done based on expert assessment, the overall distribution of successfully maintained items is 40 items which include components of interpersonal conflict (10 items) maintained, emotional disorder maintained $(10$ items), depression maintained (10 items) and (10 items) is retained for hopelessness. No items are dropped in this instrument. Tables 2 to 6 show the distribution of CVR advanced test items through expert evaluation by component.

\section{DISCUSSION}

Based on the CVR values shown in this study which are compared to the instrument validity categorization shown in Table 1, in general, the items of SIBA instruments had been classified as very high validation because the CVR value was in the range of $\leq 1.00$ and $>0.80$ (accepted). ${ }^{23}$ However, some items were still classified as high validity because the CVR value was in the range of $\leq 0.80$ and $>0.60$ (Accepted). ${ }^{23}$ Although in general, the results of the study had been able to show the categorization of SIBA instrument validity appropriately by using CVR Formula, problems were still encountered in this study. One of the problems is that the value of content validity has not been shown for the entire evaluation instrument and it is still limited to the content validity of each instrument item.

\section{CONCLUSION}

This study is about the calculation of the CVR value of the newly developed SIBA instrument items. Based on the calculated CVR value from the thorough judgement of 8 experts, only four out of 40 items are under the set critical value. It shows that SIBA has the potential to be a valid and reliable instrument to measure suicidal ideation behaviour among drug addicts in CCRC, Besut.

\section{ACKNOWLEDGEMENT}

The researcher is greatly indebted to Prof Dr. Hj Lukman Z. Mohamad for his willingness to supervise this research and to the University Sultan Zainal Abidin for giving the utmost cooperation and support.

\section{REFERENCES}

1. Szanto, K., Priberson, G., \& Reynolds, F. Suicide in the elderly. Clinical Neuroscience Research. 2001; 1:366-376. https://doi.org/10.7466/JKHMA. 2014.32.5.207

2. Van Orden, K.; Conwell, Y. Suicides in late life. Curr. Current Psychiatry Reports. 2011; 13:234-241. DOI: https://doi.org/10.1007/s11920-011-0193-3

3. Conwell, Y., Thompson, C. Suicidal behavior in elders. Psychiatr. Clinics of North America. 2008; 31:333-356. doi: https://doi.org/10.1016/j.psc.2008.01.004.
4. Conejero, I.; Olié, E.; Courtet, P.; Calati, R. Suicide in older adults: Current perspectives. Clinical Interventions, Aging. 2018; 13:691-699. doi: https://doi.org/10.2147/CIA.S130670.

5. Lima, D. D., Azevedo, R. C. S., Gaspar, K. C.., Silva, V. F., Mauro, M. .L. .F., \& Botega, N. J. Suicide attempt amongst patients with alcohol misuse admitted to a general hospital. Brazillian Journal of Psychiatry, 2010; 59(3):167-172. DOI: https://doi.org/10.1590/S0047-20852010000300001

6. World Health Organization. (2017). Global Health Observatory. Retrieved from http://www.who.int/gho/mental_health/suicide_rates/en

7. National Institute of Mental Health. Suicide. Retrieved from https://www.nimh.nih.gov/health/statistics/suicide.shtm. 2018.

8. Global Burden of Disease Collaborative Network. Global Burden of Disease Study 2017 (GBD 2017) Results. Seattle. United States: Institute for Health Metrics and Evaluation (IHME). 2018.

9. Inman, D., van Bakergem, K., LaRosa, A., \& Carr, D. Evidencebased health promotion programs for school and communities American Journal of Preventive Medicine, 2011; 40:207-219. doi: https://doi.org/10.1016/j.amepre.2010.10.031.

10. Taylor \& Jacqueline. Illegal Drug Use, Suicidal Ideation, and Attempted Suicide Among New York Adolescents. Walden Dissertations and Doctoral Studies, 5663. 2018.

11. National Survey of Drug Use and Health. The NSDUH Report: Suicidal Thoughts and Behaviours Among Adults. Rockville, MD: Substance Abuse and Mental Health Services Administration. 2018.

12. Norashida, S. R., Norshahira, O., Lukman, Z. M. Content Validity of Drug Addiction Recovery Test Instruments Using Content Validity Ratio (CVR) Method, Journal of Drug Delivery and Therapeutics. 2021; 11(4):24-29. DOI: http://dx.doi.org/10.22270/jddt.v11i4.4949.

13. Delgado, R. E., Carretero-Dios, H., \& Ruch, W. Content validity evidences in test development: An applied perspective. International Journal of Clinical and Health Psychology, 2012; 12(3):449-460. https://doi.org/10.5167/uzh-64551

14. Field, A. Discovering Statistics Using IBM SPSS Statistics. 5th Ed., London: Sage Publications Ltd, 2018.

15. DeVellis, R. F., Scale Development Theory and Applications. 4th Ed. London: SAGE Publication Inc, 2017.

16. Furr, R. M., Scale Construction and Psychometrics for Social and Personality Psychology. London: SAGE Publications Inc. 2014.

17. Ghazali Darusalam \& Sufean Hussin. Metodologi Penyelidikan Dalam Pendidikan: Amalan Dan Analisis Kajian. Kuala Lumpur: Penerbit Universiti Malaya. 2016.

18. Taherdoost, H., Validity and Reliability of the Research Instrument; How to Test the Validation of a Questionnaire/Survey in a Research, International Journal of Academic Research in Management (IJARM), 2016; 5(3):28-36. https://doi.org/10.2139/ssrn.3205040

19. Doustmohammadian, A., Omidvar, N., KeshavarzMohammadi, N., Abdollahi, M., Amini, M. and Eini Zinab, H., Developing and validating a scale to measure Food and Nutrition Literacy (FNLIT) in elementary school children in Iran., PLoS ONE 2017; 12(6):1-18. https://doi.org/10.1371/journal.pone.0179196

20. Mohd Effendi Ewan, Mohd Matore, Hisyam, sani Idris, Normawati Abdul Rahman and Ahmad Zamri Khairani. Kesahan Kandungan Pakar Instrumen IKBAR Bagi Pengukuran AQ Menggunakan Nisbah Kesahan Kandungan. Proseeding of International Conference On Global Education V (ICGE V) (May), 2017; 979- 997.

21. P. M. Dewantara, "Stake evaluation model (countenance model) in learning process bahasa indonesia at Ganesha university of educational," International Journal of English and Literature, 2017; 1(1):19-29. https://doi.org/10.23887/ijll.v1i1.9615 
22. C. Ayre and A. J. Scally, "Critical values for lawshe's content validity ratio: revisiting the original methods of calculation," Measurement and Evaluation in Counseling and Development, 2014; 47(1):79-86.

https://doi.org/10.1177/0748175613513808

23. Lawshe, C. H. A quantitative approach to content validity. Personnel Psychology, 1975; 28(4):563-575. https://doi.org/10.1111/j.1744-6570.1975.tb01393.x

24. Brinkman, W. P., Design of a questionnaire instrument handbook of mobile technology research methods. Handbook of Mobile Technology Research Methods, 2009; 31-57.
25. Pallant. SPSS Survival Manual A Step by Step Guide to Data Analysis using SPSS for Windows, 4rd Edition, Crows West: New South Wales, 2010

26. Cohen, R. J. \& Swerdlik, M. E. Psychological Testing and Assessment: An Introduction to Tests and Measurement. 9th ed. New York: McGraw Hill, 2013.

27. Haladyna, T. Developing and Validating Multiple-Choice Test Items. New York: Lawrence Erlbaum Associates, 2004. https://doi.org/10.4324/9780203825945

Table 2: The Calculating Results from Contents Validity of interpersonal conflic component item

\begin{tabular}{|l|l|l|l|l|l|}
\hline $\mathbf{N o}$ & Item & $\mathbf{N}^{*}$ & $\mathbf{N e}^{*}$ & CVR** & Interpretation \\
\hline 1 & I feel like trouble people around me a lot. & 8 & 8 & 1.00 & Accepted \\
\hline 2 & I feel like I often have a bad luck compared to people around me. & 8 & 6 & 0.75 & Accepted \\
\hline 3 & I feel too intimidated by people around me. & 8 & 7 & 0.88 & Accepted \\
\hline 4 & I feel useless to other people. & 8 & 8 & 1.00 & Accepted \\
\hline 5 & I feel like I am often victimised by people around me. & 8 & 5 & 0.63 & Accepted \\
\hline 6 & I feel like people around me are not concerned about me. & 8 & 6 & 0.75 & Accepted \\
\hline 7 & I feel like people around me really despise me. & 8 & 6 & 0.75 & Accepted \\
\hline 8 & I feel people around me often distance themselves from me. & 8 & 8 & 1.00 & Accepted \\
\hline 9 & I feel like people around me often betray me. & 8 & 6 & 0.75 & Accepted \\
\hline 10 & I feel like people around me often blame me for something that happens. & 8 & 8 & 1.00 & Accepted \\
\hline
\end{tabular}

Note: * The number of expert panels that have selected an item as very important (important).

** Content Validity Ratio (CVR) = (Ne-N / 2) / (N / 2) using an expert panel of experts (N = 8), items with a CVR value of 0.6 and above were retained as instruments.

Table 3: The Calculating Results from Contents Validity of emotional disorder component item

\begin{tabular}{|c|c|c|c|c|c|}
\hline No & Item & $\mathbf{N}^{*}$ & $\mathrm{Ne}^{*}$ & CVR $^{* *}$ & Interpretation \\
\hline 11 & I often feel uneasy (stressed out) every time I wake up in the morning. & 8 & 5 & 0.63 & Accepted \\
\hline 12 & I often feel like my life is meaningless and boring. & 8 & 8 & 1.00 & Accepted \\
\hline 13 & I often experience uncontrollable sad feeling & 8 & 5 & 0.63 & Accepted \\
\hline 14 & I often experience nightmares or bad dream. & 8 & 5 & 0.63 & Accepted \\
\hline 15 & $\begin{array}{l}\text { I often have insufficient sleep, am tired and perplexed when facing big } \\
\text { problem. }\end{array}$ & 8 & 8 & 1.00 & Accepted \\
\hline 16 & I am often angry with myself when failed to solve the problem I have. & 8 & 6 & 0.75 & Accepted \\
\hline 17 & $\begin{array}{l}\text { My emotion is easily disturbed or becomes worst when experiencing } \\
\text { stress in life. }\end{array}$ & 8 & 5 & 0.63 & Accepted \\
\hline 18 & I often experience headache, neck pain or nausea at least once a month. & 8 & 5 & 0.63 & Accepted \\
\hline 19 & $\begin{array}{l}\text { I often go on rampage or destroy property whenever I have problem or } \\
\text { stress in life. }\end{array}$ & 8 & 8 & 1.00 & Accepted \\
\hline 20 & $\begin{array}{l}\text { I was once advised by a doctor to take certain medications or undergo } \\
\text { mental health treatment. }\end{array}$ & 8 & 5 & 0.63 & Accepted \\
\hline
\end{tabular}

Note: * The number of expert panels that have selected an item as very important (important).

** Content Validity Ratio $(\mathrm{CVR})=(\mathrm{Ne}-\mathrm{N} / 2) /(\mathrm{N} / 2)$ using an expert panel of experts $(\mathrm{N}=8)$, items with a CVR value of 0.6 and above were retained as instruments. 
Table 4: The Calculating Results from Contents Validity of dipression component item

\begin{tabular}{|c|c|c|c|c|c|}
\hline No & Item & $\mathbf{N}^{*}$ & $\mathrm{Ne}^{*}$ & CVR $^{* *}$ & Interpretation \\
\hline 21 & I often feel lethargic or lack of energy. & 8 & 6 & 0.75 & Accepted \\
\hline 22 & I often feel guilty thinking what had happened to me. & 8 & 7 & 0.88 & Accepted \\
\hline 23 & I have taken drugs excessively before. & 8 & 5 & 0.63 & Accepted \\
\hline 24 & I often take my physical health for granted. & 8 & 5 & 0.63 & Accepted \\
\hline 25 & I prefer to be alone or isolate myself from family and friends. & 8 & 7 & 0.88 & Accepted \\
\hline 26 & $\begin{array}{l}\text { I lost interest or excitement to carry out activities that I used to do } \\
\text { before. }\end{array}$ & 8 & 6 & 0.75 & Accepted \\
\hline 27 & I was once reprimanded for talking by myself. & 8 & 6 & 0.75 & Accepted \\
\hline 28 & I often experience sent angled mind that affects the sanity of my action. & 8 & 5 & 0.63 & Accepted \\
\hline 29 & I often experience high emotional pressure in a long period. & 8 & 6 & 0.75 & Accepted \\
\hline 30 & $\begin{array}{l}\text { I was advised to refer to the hospital for behaving strangely or doing } \\
\text { something strange. }\end{array}$ & 8 & 8 & 1.00 & Accepted \\
\hline
\end{tabular}

Note: $*$ The number of expert panels that have selected an item as very important (important).

** Content Validity Ratio (CVR) = (Ne-N / 2) / (N / 2) using an expert panel of experts (N = 8), items with a CVR value of 0.6 and above were retained as instruments.

Table 5: The Calculating Results from Contents Validity of hopelessness component item

\begin{tabular}{|l|l|l|l|l|l|}
\hline No & Item & $\mathbf{N}^{*}$ & $\mathbf{N e}$ & CVR** & Interpretation \\
\hline 31 & I feel like this life has long been ruined and can never be restored. & 8 & 7 & 0.88 & Accepted \\
\hline 32 & I never work on rising again for a better life direction. & 8 & 8 & 1.00 & Accepted \\
\hline 33 & I unable to control myself well and feel sad and angry towards myself. & 8 & 7 & 0.88 & Accepted \\
\hline 34 & I feel disappointed with myself and very ashamed to go on with this life. & 8 & 7 & 0.88 & Accepted \\
\hline 35 & I feel very lonely and need to end this feeling with death. & 8 & 6 & 0.75 & Accepted \\
\hline 36 & $\begin{array}{l}\text { I failed to live my life like everyone else and feel that death is the best } \\
\text { way for me. }\end{array}$ & 8 & 6 & 0.75 & Accepted \\
\hline 37 & I feel like I have long been dead. & 8 & 5 & 0.63 & Accepted \\
\hline 38 & I often imagine death when experience stress in life. & 8 & 8 & 1.00 & Accepted \\
\hline 39 & I think more about death as opposed to my life in the future. & 8 & 7 & 0.88 & Accepted \\
\hline 40 & I often feel death is the best solution of the problem that I have in life. & 8 & 5 & 0.63 & Accepted \\
\hline
\end{tabular}

** Content Validity Ratio (CVR) = (Ne-N / 2) / ( N / 2) using an expert panel of experts $(\mathrm{N}=8)$, items with a CVR value of 0.6 and above were retained as instruments.

Table 6: Item Distribution after Expert Verification and CVR Test

\begin{tabular}{|l|l|l|}
\hline Component & Item No & Item Are Rejected \\
\hline Conflict Interpersonal & $1,2,3,4,5,6,7,8,9,10$ & None \\
\hline Emotional Disorder & $11.12 .13,14,15,16,17,18,19,20$ & None \\
\hline Depression & $21,22,23,24,25,26,27,28,29,30$ & None \\
\hline Hopelessness & $31,32,33,34,35,36,37,38,39,40$ & None \\
\hline
\end{tabular}

